\title{
Effect of heel elevation on breakover phase in horses with laminitis
}

\author{
Mohamad Al Naem ${ }^{1 *}$ (D), Lutz-Ferdinand Litzke ${ }^{1}$, Florian Geburek², Klaus Failing ${ }^{3}$, Johanna Hoffmann ${ }^{1}$ and \\ Michael Röcken ${ }^{1}$
}

\begin{abstract}
Background: In a laminitic horse, the maximal loading of the toe region occurs during the breakover phase. To date, no kinetic data demonstrates the effect of supportive orthopaedic therapy in horses with laminitis on breakover phase. Thus, the purpose of this study was to examine the effect of heel elevation on the breakover phase. Eight horses with acute laminitis treated medically as well as with application of a hoof cast with heel wedge (HCHW) were included in this study. Immediately following cessation of clinical signs of acute laminitis, two measurements using the Hoof ${ }^{\mathrm{rm}}$ System were taken: the first with $\mathrm{HCHW}$ and the second immediately following removal of the $\mathrm{HCHW}$, i.e. in barefoot condition (BFC). The hoof print was divided into three regions: toe, middle hoof, and heel. Kinetic parameters included vertical force (VF), stance duration, contact area (CA) for all hoof regions during stance phase, duration of breakover, VF in the toe region at onset of breakover and location of centre of force.

Results: The VF and CA were higher in the heel region (63 and 61\%, respectively) and decreased significantly after removal of the HCHW (43 and 28\% after removal, respectively). The breakover phase in horses with HCHW lasted $2 \%$ of stance phase and was significantly shorter than that in BFC, which lasted $6 \%$ of stance phase. The VF at onset of breakover for the toe region in horses with $\mathrm{HCHW}$ was significantly lower than that in BFC. The centre of the force was located at the heel region in all horses with the HCHW, and at the middle the hoof region in BFC.

Conclusions: Heel elevation in horses with laminitis as examined on a concrete surface significantly shortens breakover phase and decreases the vertical force in the toe region during breakover. HCHW provides adequate support to the palmar hoof structures by increasing the contact area in the heel region and incorporating the palmar part of frog and sole into weight bearing, thus decreasing the stress on the lamellae. Hoof cast with heel elevation could be a beneficial orthopaedic supportive therapy for horses suffering from acute laminitis.
\end{abstract}

Keywords: Heel elevation, Hoof kinetics, Hoof ${ }^{\mathrm{rm}}$ system, Horse, Laminitis

\section{Background}

Acute laminitis is defined as the onset of clinical signs including bounding digital pulse, increased heat at the coronary band in combination with a positive response to the hoof tester over the toe. Moreover, affected horses display a stilted gait and are reluctant to move [1, 2].

\footnotetext{
* Correspondence: Mohamad.Al-Naem@vetmed.uni-giessen.de

${ }^{1}$ Clinic for Horses (Surgery, Orthopaedics), Faculty of Veterinary Medicine, Justus-Liebig-University, Giessen, Frankfurter str. 108, 35392 Giessen, Germany Full list of author information is available at the end of the article
}

The goal of supportive orthopaedic therapy for horses with acute laminitis is to shift the load from the diseased and most painful areas of the hoof to the undamaged areas $[3,4]$. Recently, a kinetic study demonstrated that the maximal loading of the toe region in horses with laminitis occurred during breakover phase and that the main shift of the load within the hooves of laminitic horses occurred between the toe and middle hoof regions. Moreover, in laminitic horses, relative vertical force and vertical impulse were higher in the heel region

(C) The Author(s). 2020, Corrected publication. December 2020. Open Access This article is licensed under a Creative Commons Attribution 4.0 International License, which permits use, sharing, adaptation, distribution and reproduction in any medium or format, as long as you give appropriate credit to the original author(s) and the source, provide a link to the Creative Commons licence, and indicate if changes were made. The images or other third party material in this article are included in the article's Creative Commons licence, unless indicated otherwise in a credit line to the material. If material is not included in the article's Creative Commons licence and your intended use is not permitted by statutory regulation or exceeds the permitted use, you will need to obtain permission directly from the copyright holder. To view a copy of this licence, visit http://creativecommons.org/licenses/by/4.0/. The Creative Commons Public Domain Dedication waiver (http:// creativecommons.org/publicdomain/zero/1.0/) applies to the data made available in this article, unless otherwise stated in a credit line to the data. 
than in other regions, while in the sound horses, relative vertical force and vertical impulse were the highest in the toe region $[5,6]$. . Thus, easing the breakover phase which is the time from heel-off to toe-off [7], should be considered when treating horses with laminitis to minimize the load on the damaged lamellae in the toe region [6]. A variety of supportive orthopaedics therapy options are available for horses with acute laminitis including hoof cast with heel wedge (HCHW) [3], lily pad, toe bevelling [8], and wooden shoes [9]. However, to the best of our knowledge, no data are available in the literature demonstrating the effects of these treatments on hoof kinetics. Thus, the purpose of this study was to examine the effect of heel elevation on the breakover phase and the vertical force in the toe region during breakover phase as well as the contact area in the heel region in horses with laminitis. We hypothesized that the breakover phase would be shorter in laminitic horses with $\mathrm{HCHW}$ as compared to the same horses following removal of the HCHW.

\section{Results}

History and clinical as well as radiographic findings are listed in Tables 1 and 2.

There were no significant differences in any of the variables between the left and right forelimbs ( $t$-test for dependent samples). Therefore, the measured variables for both limbs were pooled by using arithmetic mean over both sides.

In the toe region, the CA was significantly higher following removal of the $\mathrm{HCHW}(p=0.002)$ (Fig. 1). For the VF, there were no significant changes. The VF at tHO for the toe region in horses with HCHW was significantly $(p<0.001)$ lower than those in BFC (Table 3).

In the middle hoof region, the $\mathrm{VF}$ and $\mathrm{CA}$ increased significantly following removal of the HCHW ( $p=0.002$, $p=0.001$, respectively) (Table 3 ).

In horses with the $\mathrm{HCHW}$, the $\mathrm{VF}$ and $\mathrm{CA}$ were higher in the heel region and decreased significantly $(p=0.001$ and $p=0.001$ respectively) after removal of the HCHW (Figs. 1, 2). The mean stance phase duration did not significantly differ between the two conditions (HCHW vs BFC) $(p=0.38)$. The breakover phase in horses with HCHW (tHO $98 \pm 1.2 \%$ of stance phase) lasted $2 \%$ of the stance phase and was significantly shorter than those in BFC (tHO 94 $\pm 1.3 \%)$, which lasted $6 \%$ of stance phase (Fig. 3).

The centre of the force was located at the heel region in all horses with the $\mathrm{HCHW}$, whereas it was located at the middle hoof region in laminitic horses in the BFC. A representative example of one forehoof measurement of a horse (number 6) with laminitis following application of the HCHW and in the BFC is shown in Fig. 4.

\section{Discussion}

To the best of our knowledge, the study presented here is the first kinetic study to examine the effect of heel elevation on breakover phase in horses with laminitis.

Our results demonstrate that the breakover phase in laminitic horses with $\mathrm{HCHW}$ was significantly shorter than those in BFC. Onset and duration of breakover phase are highly dependent on hoof angle and toe length [7]. Breakover phase is significantly longer in horses with a long toe, as it acts as a long lever arm [10]. Our results can be explained by the fact that heel elevation causes the dorsal hoof wall to be more upright, promoting an earlier breakover. Furthermore, the load of the toe region was significantly lower in horses with $\mathrm{HCHW}$ during breakover phase as compared to those in BFC. This is attributed to ease of breakover reducing the time at which the forces acting on the damaged lamellae in the toe region as well as to a palmar shift of the centre of force to the heel region. Consequently, $\mathrm{HCHW}$ has the potential to provide relief from pain caused by the damaged lamellae in horses with laminitis.

A recently presented kinetic study demonstrated that in laminitic horses the VF in the heel region was significantly higher as compared to toe and middle hoof regions, whereas the VF in the toe region was highest in sound horses [5]. Therefore, supporting the heel region should be considered when treating laminitic horses. In this context, our results showed that, in horses with an

Table 1 signalment and anamnestic details of the horses

\begin{tabular}{|c|c|c|c|c|c|c|}
\hline Number & Breed & Sex & Age (year) & Weight (kg) & Number of laminitic episodes & Reason for laminitis \\
\hline 1 & Icelandic horse & Gelding & 8 & 440 & 1 & Colic episode \\
\hline 2 & Welsh pony & Mare & 13 & 343 & 1 & NA \\
\hline 3 & Warmblood & Mare & 15 & 550 & 1 & Change in exercise routine \\
\hline 4 & Icelandic horse & Gelding & 10 & 400 & 2 & NA \\
\hline 5 & Welsh pony & Gelding & 22 & 330 & 2 & Cushing's disease \\
\hline 6 & Arabian horse & Gelding & 18 & 410 & 1 & Pasture-associated laminitis \\
\hline 7 & Icelandic horse & Mare & 15 & 455 & 1 & Change in exercise \\
\hline 8 & Quarter horse & Mare & 9 & 475 & 1 & NA \\
\hline
\end{tabular}


Table 2 Summary of the results of clinical as well as radiographic examination of the most severely affected forelimb

\begin{tabular}{|c|c|c|c|c|c|c|}
\hline Number & $\begin{array}{l}\text { Obel-grade on } \\
\text { admission }\end{array}$ & $\begin{array}{l}\text { Obel-grade after } \\
\text { application of } \mathrm{HCHW}\end{array}$ & $\begin{array}{l}\text { Degree of } \\
\text { phalanx rotation }\end{array}$ & Sole depth $(\mathrm{mm})$ & $\begin{array}{l}\text { Time of } \\
\text { hospitalization } \\
\text { (days) }\end{array}$ & $\begin{array}{l}\text { Duration of } \\
\text { application of } \\
\text { HCHW (days) }\end{array}$ \\
\hline 1 & 2 & $1-2$ & 6 & 11.4 & 13 & 12 \\
\hline 2 & 3 & 2 & 9 & 9.3 & 14 & 13 \\
\hline 3 & 1 & $0-1$ & 3 & 14.3 & 8 & 7 \\
\hline 4 & 3 & 2 & 7 & 11 & 12 & 11 \\
\hline 5 & 2 & 1 & 6 & 11.4 & 10 & 9 \\
\hline 6 & 3 & 2 & 10 & 9.6 & 18 & 17 \\
\hline 7 & 2 & 1 & 4 & 11.5 & 12 & 11 \\
\hline 8 & 2 & 1 & 6 & 13.6 & 15 & 14 \\
\hline
\end{tabular}

HCHW, the total hoof contact area of the heel region was significantly higher than that observed in the BFC, resulting possibly in more comfort of the horses. Involving the sole and frog by application of an HCHW increased the contact area of the heel region and distributed the load over a larger area. A previous study demonstrated an increase in the weight-bearing contact area, a decrease of total contact pressure, and a decrease of peak contact pressure in healthy horses following the application of a foam sole support [11]. Supporting the sole and frog reduces the weight borne by the wall, thereby reducing the stress on the lamellae $[11,12]$. Moreover, all horses in this study were stalled in a box with soft bedding (peat). Placing the laminitic horses on sand or peat is beneficial in supporting the sole thus reducing the load on the hoof wall, as these substrates conform well to the foot [1]. It has been demonstrated that the contact area in clinically sound horses increases to almost double when on deep sand compared to a concrete surface [13]. Therefore, laminitic horses with $\mathrm{HCHW}$ would benefit from soft bedding due to increased contact area.

Our results showed that the VF in the heel region of laminitic horses with an $\mathrm{HCHW}$ was higher than that observed in the BFC. This finding is in agreement with that of a study demonstrating, that the load on the palmar half of the hoof constitutes $81 \%$ of the total load after heel elevation in standing horses suffering from acute laminitis [14]. Furthermore, the current study showed that the centre of force was located in the heel region in horses with $\mathrm{HCHW}$. A palmar position of the

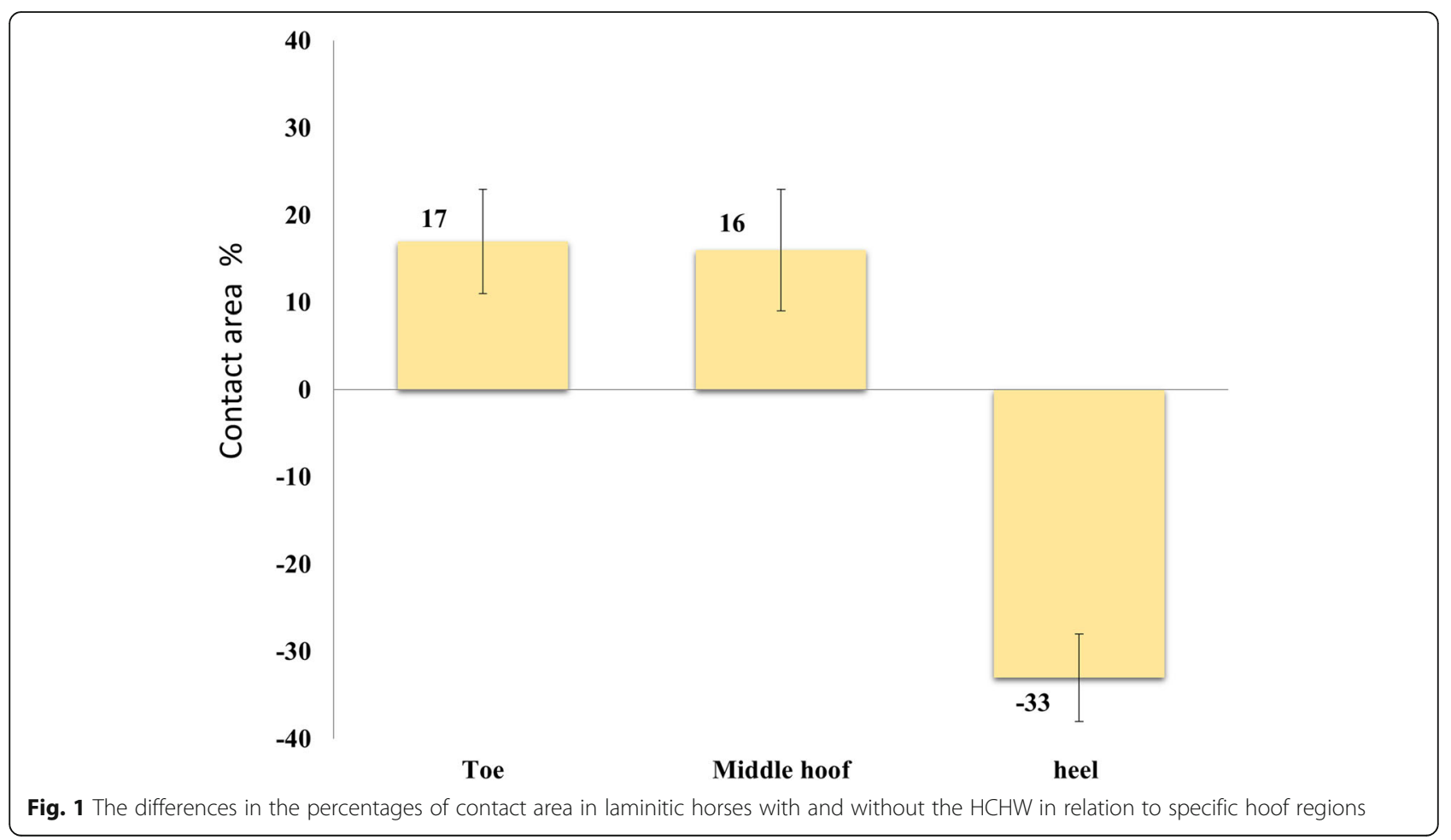


Table 3 Mean \pm standard deviation of the loading and timing variables (VF, CA, VF - tHO, StDur) of eight laminitic horses with and without the HCHW in the toe, middle hoof and heel regions

\begin{tabular}{|c|c|c|c|c|}
\hline Variables & Hoof print regions & $\mathrm{HCHW}$ & $\mathrm{BFC}$ & Difference \\
\hline \multirow[t]{3}{*}{ VF (N) } & Toe & $657 \pm 133$ & $756 \pm 99$ & $+99 \pm 65$ \\
\hline & Middle hoof & $290 \pm 46$ & $699 \pm 87$ & $+409 \pm 103^{a}$ \\
\hline & Heel & $1609 \pm 119$ & $1078 \pm 113$ & $-531 \pm 43^{a}$ \\
\hline VF - tHO & Toe & $380 \pm 221$ & $682 \pm 361 \mathrm{~N}$ & $-302 \pm 115^{a}$ \\
\hline \multirow[t]{3}{*}{$\mathrm{CA}\left(\mathrm{cm}^{2}\right)$} & Toe & $13.5 \pm 5$ & $16.9 \pm 6.9$ & $+3.4 \pm 5^{\mathrm{a}}$ \\
\hline & Middle hoof & $6.7 \pm 4.3$ & $11.7 \pm 4.2$ & $+4.4 \pm 6^{a}$ \\
\hline & Heel & $31.4 \pm 7.4$ & $11.1 \pm 3.5$ & $-20.3 \pm 8^{a}$ \\
\hline StDur (s) & The entire hoof & 0.76 & 0.79 & 0.03 \\
\hline
\end{tabular}

BFC Barefoot condition; HCHW Hoof cast with heel wedge; CA Contact area; VF Vertical force; VF-tHO Vertical force at onset of breakover, StDur Stance duration. ${ }^{a} p<0.05$

centre of pressure and elevation of the heels decrease the moment arm acting on the distal interphalangeal joint, thereby decreasing the stress that the deep digital flexor tendon exerts on the third phalanx $[9,15]$. This may help to minimize the stress in the dorsal lamellae and prevent further damage to the damaged lamellae providing ideal conditions for healing.

The proposed theory behind the use of the HCHW is to shift loading forces to the undamaged heel and frog regions to provide relief to the toe region [9]. HCHW should be considered an integral part of supportive therapy for horses with acute laminitis, keeping in mind that the palmar structures of the hoof are capable of bearing more weight [3]. This treatment has been proven to be less suitable in cases with generalized lamellar damage or sinking of the distal phalanx [16]. Moreover, the HCHW prevents hoof wall expansion and deformation which could potentially make the horse more comfortable.

Furthermore, the $\mathrm{HCHW}$ is an inexpensive, quick, and easy method to elevate the heel. The plaster bandage can be adapted to any hoof shape and moulded into the frog sulci, increasing the weight-bearing surface area. This distributes the load over a larger area without the need for impression material, which is required in other methods such as wooden shoes and the modified ultimate cuff [4]. However, crushed heels, cracks, or displaced bulbs may develop after

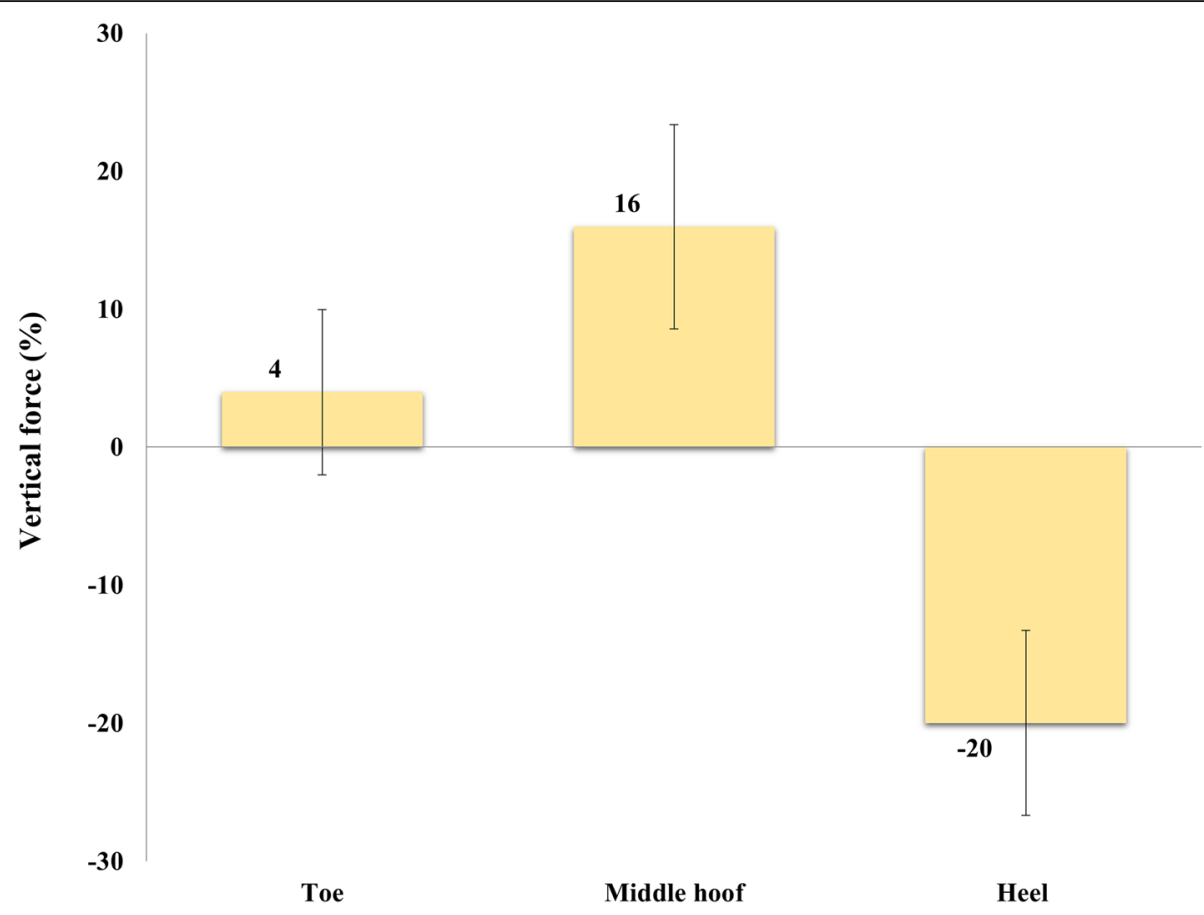

Fig. 2 The differences in the percentages of vertical force between laminitic horses with and without the HCHW in relation to specific hoof regions 

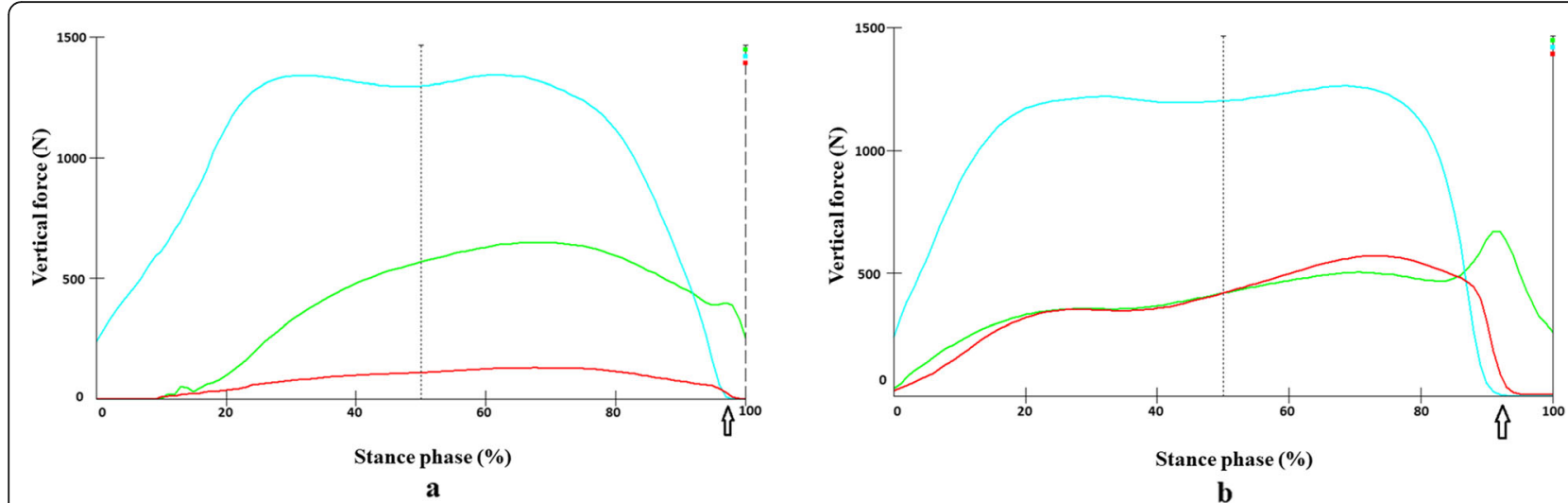

Fig. 3 Force-time-curve of the three hoof regions in a representative horse (number 6) with (a) and without an HCHW (b) during stance phase. The heel region (aqua) experienced the highest load in both conditions. The load distributions in the toe (green) and middle (red) regions of the hoof were similar in the BFC. The load in the middle hoof region (red) increased after removal of the HCHW. The arrow indicates the time at which the heel off occurred. BFC = barefoot condition; HCHW = hoof cast with heel elevation

long-term application of an HCHW [17]. Elevation of the heels may cause hoof contraction in the long term [18]. In our cases, the application time of the HCHW ranged between 7 and 17 days with no problems reported. As such and depending on our clinical observation, the application of a heel wedge should be of a limited duration (maximal 2-3 weeks).

It has been demonstrated that digital hypothermia would ameliorate experimentally induced laminitis due to the hypometabolic and anti-inflammatory effects [19], although, there is no scientific evidence regarding the effect of digital hypothermia on the treatment of horses with acute laminitis [20]. However, a cooling method entailing a water interface with the hoof that include the distal limb and foot should be used to achieve an effective cooling of the lamellar tissue [21]. The use of such methods would have caused a desintegration of the plaster of paris used in our cases. However, elevation of the heels using other materials could be considered as an option when concurrent cryotherapy is indicated.

This study had some limitations. Ideally, four measurements should have been taken: the first upon

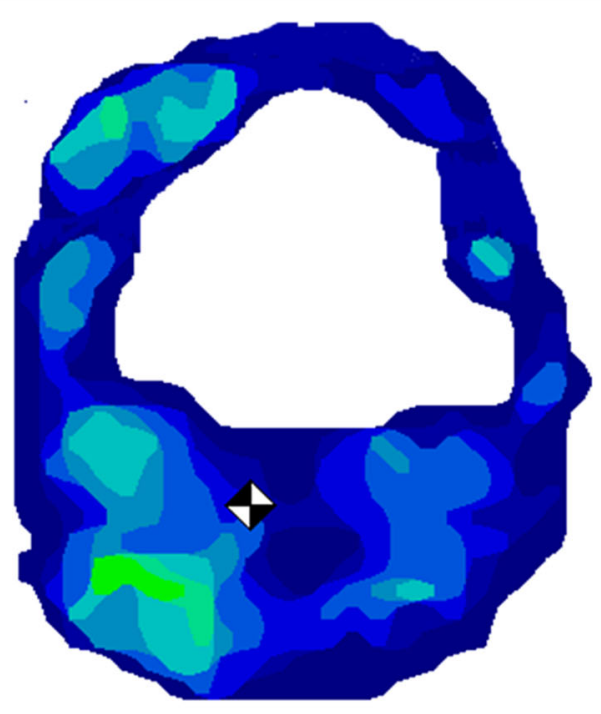

a

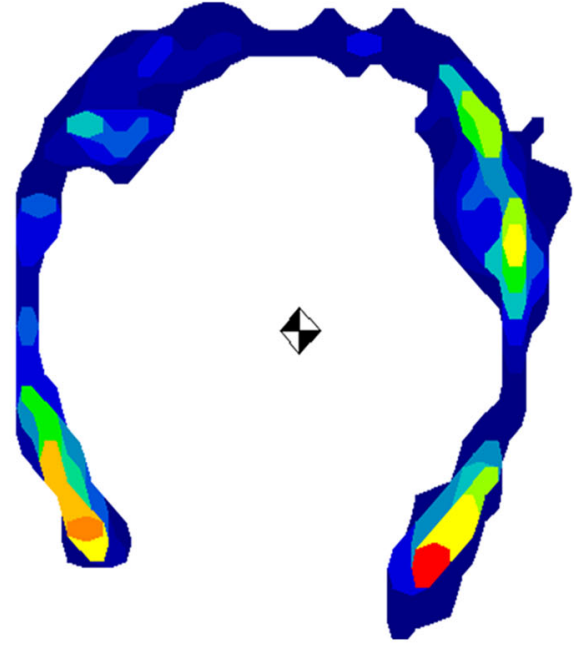

b

Fig. 4 The averaged pressure distribution with the centre of the force $(\boldsymbol{)}$ ) of a horse (number 6 ) with (a) and without the HCHW (b) during the stance phase. Lateral is to the left and dorsal is in the top. The pressure distribution is colour coded: red = highest pressure forces and deep blue $=$ lowest pressure forces, as seen on the pressure scale. With HCHW, the centre of the force was located palmary in the heel region. The hoof contact area decreased after removal of the HCHW in the heel region and the centre of the force shifted dorsally to the middle hoof region compared with $\mathrm{HCHW}$. BFC = barefoot condition; $\mathrm{HCHW}=$ hoof cast with heel elevation 
admission in the BFC during the acute phase, the second immediately after the application of the hoof cast, and the third and fourth after the acute signs had subsided with and immediately after removal the hoof cast. However, measurement prior to the application of the hoof cast would have taken place during a more acute phase, and would therefore, have been during the more painful and unstable phase of laminitis, as both application and calibration of the measuring system take about 15-20 min. Moreover, horses are required to stand during these procedures on one forelimb with the contralateral limb held off the ground for approximately $1-2 \mathrm{~min}$. Thus, there was a potential risk of further damage to the lamellae, which could have a negative effect on the healing process. Therefore, we only took two measurements, as opposed to four. Other limitations include the small sample size and the variation in breeds included in the study. Laminitis is not a very common disease in horses, so we were forced to include horses from different breeds and sizes. Furthermore, there was not a normal control group in the study; however, the forelimbs from each horse were subjected to two measurements and served as its own control.

\section{Conclusions}

The current study demonstrated that heel elevation in horses with laminitis as examined on a concrete significantly shortens breakover phase and decreases the vertical force in the toe region during breakover. HCHW provides adequate support to the palmar hoof structures by increasing the contact area in the heel region and incorporating the palmar part of frog, sole and into weight bearing, thus decreasing the stress on the lamellae. Hoof cast with heel elevation could be a beneficial orthopaedic supportive therapy for horses suffering from acute laminitis.

\section{Methods \\ Horses}

Horses with clinical signs of acute laminitis that were admitted to the Clinic for Horses of the Justus-LiebigUniversity in Gießen, Germany were included in the study prospectively within a period of 1 year. Inclusion criteria were horses suffering from acute laminitis (initial or recurrence episodes) on both forelimbs with rotation of the distal phalanx. Horses with distal displacement of the distal phalanx, horses affected on only one forelimb or on hindlimbs, as well as those with dorsal capsular rotation were excluded from the study.

Diagnosis of acute laminitis was based on the results of clinical and lameness examination (bounding digital pulse, excessive heat in the feet, positive response to hoof tester and the typical stilted gait) [2], as well as radiographic finding (rotation of phalanx and decreased the sole depth) [22] associated with the acute laminitis. Following diagnosis, lameness was evaluated and graded subjectively according to Obel-grades [23]. If the horses were shod, horseshoes were removed and subsequently, an $\mathrm{HCHW}$ was applied on both forelimbs as described previously (supplementary material) [16] (Fig. 5). The gait was re-evaluated subjectively, no kinetic measurements were performed during the acute phase in order to avoid further damage to the sensitive lamellae.

Thereafter horses received medical therapy consisting of meloxicam $(0.6 \mathrm{mg} / \mathrm{kg}$, SID orally) acepromazine $(0.01 \mathrm{mg} / \mathrm{kg}, \mathrm{BW}$, TID orally) and dalteparin-sodium (50 $\mathrm{IU} / \mathrm{kg}, \mathrm{BW}, \mathrm{SID}, \mathrm{SC}$ ) and were stalled in a box with a soft bedding (peat). One horse with equine pituitary pars intermedia disease received pergolide mesylate $(2 \mu \mathrm{g} / \mathrm{kg}$, BW, SID orally). Moreover, all horses received soaked hay $1 \mathrm{~kg} / 100 \mathrm{~kg} /$ day. After resolution of the acute signs of laminitis, all medications were discontinued, however the dose of meloxicam was reduced gradually over 2 days and then completely discontinued. The acute episode of laminitis was considered to be overcome when the horses with $\mathrm{HCHW}$ were sound at a walk without medication while walking on hard as well as on soft surfaces. Thereafter, the horses were equipped with the Hoof $^{\mathrm{im}}$ System on both forelimbs and two measurements were performed as described in a previous study [6]. The first measurement took place prior to removing the $\mathrm{HCHW}$. The second measurement was performed immediately following removal of the HCHW. Data were acquired at a walk in a straight line on an indoor $3 \times 15$ $m$ track with a level concrete surface allowing the measurement of 7-11 strides.

\section{Data processing}

To evaluate the kinetic data of the pressure measurement system, the mean of 5 valid strides was calculated and averaged into one pressure image using the FastSCAN Mobile Research software program (version 6.34, TekScan Inc., South Boston). Each individual hoof print was divided into three equal regions by two lines: the toe, middle hoof, and heel (Fig. 6). The following kinetic parameters were calculated and analysed for each region: vertical force (VF) was defined as the force measured by all sensing elements $\left(\mathrm{N}\right.$ and \%); hoof contact area $(\mathrm{CA})\left(\mathrm{cm}^{2}\right.$ and \%) was defined as the surface area of all loaded sensing elements. Stance phase duration (sec) and the breakover phase, which starts at the time of heel-off (tHO) (\% of stance phase), which is the time at which the heel is lifted off the ground, and ends at time of toe-off (end of stance phase), were also recorded. Furthermore, vertical force (Newton) at time of heel-off (VF-tHO) (only for the toe region) was 


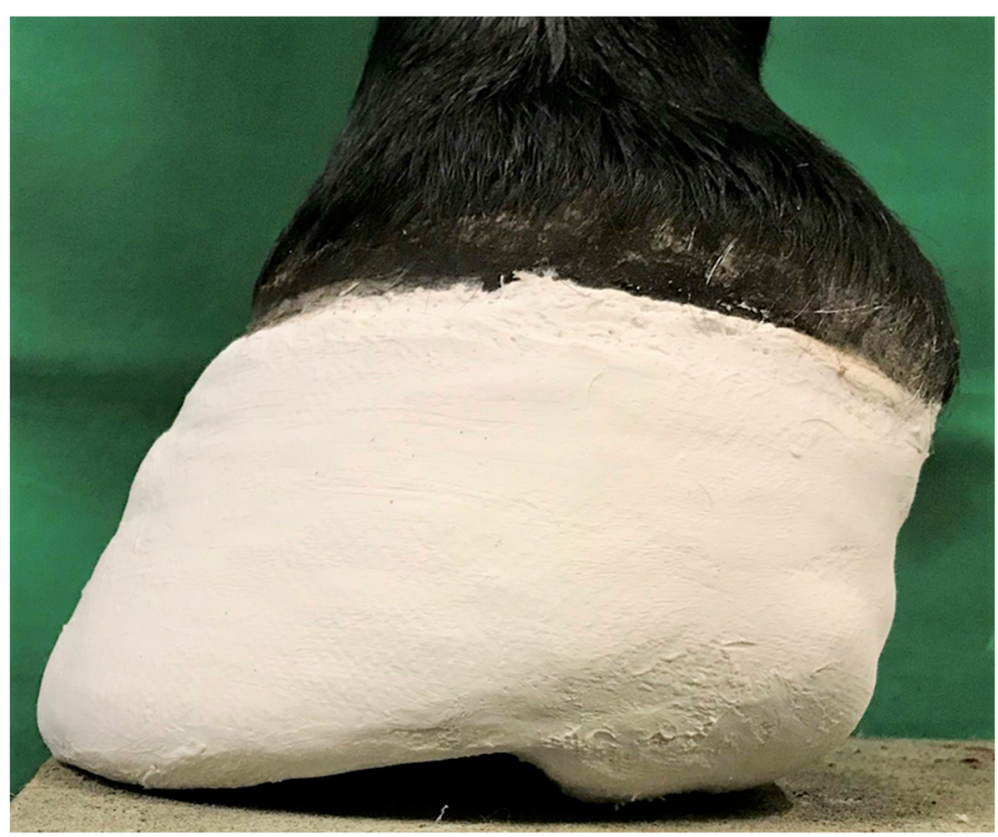

Fig. 5 Hoof cast with heel wedge made from Plaster of Paris

also calculated. Moreover, the location of centre of force was recorded.

\section{Statistical analysis}

For each variable, the data were analysed using two-way repeated-measures analysis of variance (ANOVAs). Side (left and right forelimb) and hoof region were considered as fixed effects. The measured HCHW values were compared to the barefoot values. The difference between the two measurements (the mean value of the $\mathrm{HCHW}$ condition minus the mean value of the BFC) for each hoof region was computed and analysed. Afterward, pairwise comparisons were computed for each of the hoof regions using dependent samples $t$-tests, which incorporated the mean square error term of the ANOVA. Type I error inflation was controlled with a Bonferroni-Holm correction.

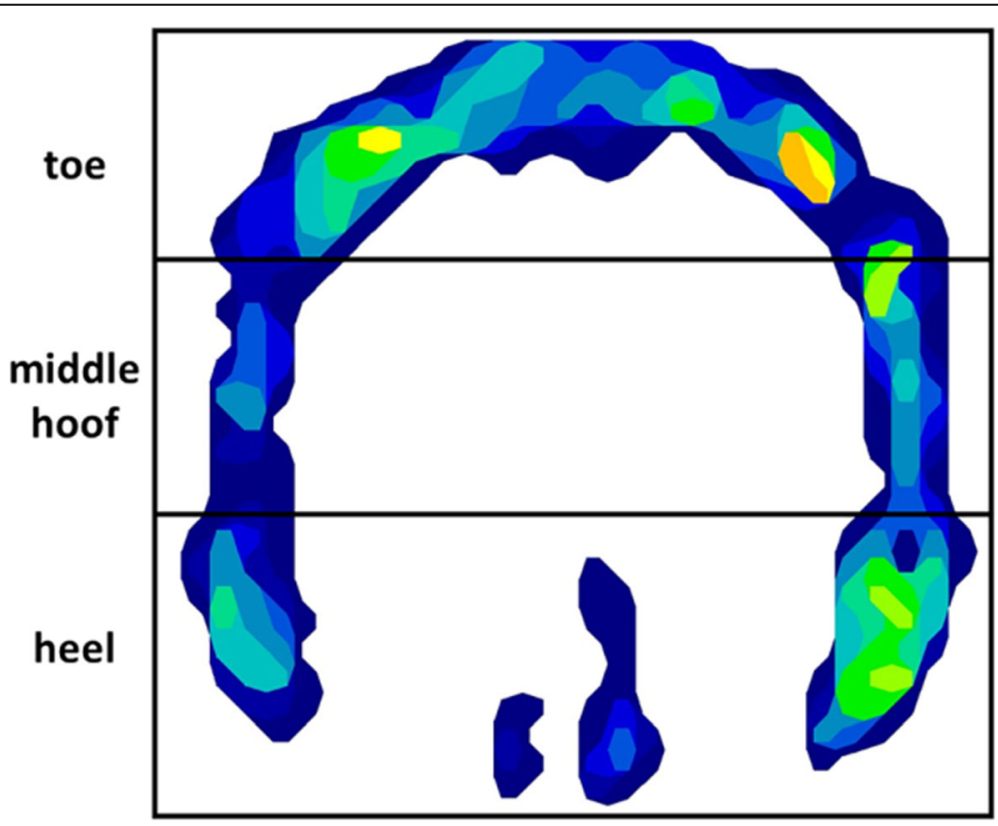

Fig. 6 Exemplary hoof print, divided by two lines into the three regions (toe, middle hoof and heel) 
Data were statistically analysed using BMDP2V statistical software (Statistical Software, Los Angeles, CA, USA). Pvalues $<0.05$ were considered as statistically significant.

\section{Supplementary information}

Supplementary information accompanies this paper at https://doi.org/10. 1186/s12917-020-02571-5.

\section{Additional file 1}

\section{Abbreviation}

HCHW: Hoof cast with heel wedge; BFC: Bare foot condition; SC: Subcutaneous; VF: Vertical force; tHO: Time of heel-off; VF-tHO: Vertical force at time of heel-off; CA: Contact area; StDur: Stance duration; N: Newton; SID: Once a day; TID: Three time daily; BW: Body weight; sec: Second

\section{Acknowledgments}

The authors would like to acknowledge Mr. Andreas Schaubmar for his statistical advice.

\section{Authors' contributions}

$L L, M R$ and MA conceived the study. MA performed the measurements. KF performend the staistical analysis. MA wrote the manuscript. FG and $\mathrm{JH}$ revised the Manuscript. All authors read and approved the final manuscript.

\section{Funding}

This research did not receive any specific grant from funding agencies in the public, commercial, or not-for-profit sectors. Open Access funding enabled and organized by Projekt DEAL.

\section{Availability of data and materials}

The datasets used and/or analyzed during the current study are available from the corresponding author on reasonable request.

\section{Ethics approval and consent to participate}

The study was approved by the animal welfare officer at the Justus-liebig University and local Government in Giessen - Hessen 23.10.2018 as nonexperimental and the Reference number is 54-19 c 2015 h 02 Gl 18/13 kTV 10/2018. All owners gave informed consent (verbal) for their horses' inclusion in the study. Written consent was unnecessary as, the study was approved as non-experimental study. The animal welfare officer approved the verbal consent.

\section{Consent for publication}

Not applicable.

\section{Competing interests}

None.

\section{Author details}

${ }^{1}$ Clinic for Horses (Surgery, Orthopaedics), Faculty of Veterinary Medicine, Justus-Liebig-University, Giessen, Frankfurter str. 108, 35392 Giessen, Germany. ${ }^{2}$ Clinic for Horses, University of Veterinary Medicine Hannover, Foundation, Hannover, Bünteweg 9, 30559 Hannover, Germany. ${ }^{3}$ Unit for Biomathematics and Data Processing, Justus-Liebig-University, Giessen, Frankfurter Str. 95, 35392 Giessen, Germany.

Received: 12 February 2020 Accepted: 15 September 2020 Published online: 01 October 2020

\section{References}

1. Van Eps AW. Acute laminitis: medical and supportive therapy. Vet Clin North Am Equine Pract. 2010;26:103-14

2. Baker WR Jr. Treating laminitis. Beyond the mechanics of trimming and shoeing. Vet Clin North Am Equine Pract. 2012:28:441-55.

3. Huskamp B. Some notes for the orthopedic treatment of laminitis (Anmerkungen zur orthopädischen Behandlung der Hufrehe). Pferdeheilkunde. 1990;6:3-9.
4. Reily PT, Dean EK, Orsini JA. First aid for the laminitic foot: therapeutic and mechanical support. Vet Clin North Am Equine Pract. 2010;26:451-8.

5. Al Naem M, Geburek F, Röcken M, Litzke LF. Investigation of the load distribution pattern in laminitic horses using hoof ${ }^{\mathrm{TM}}$ system. Scientific presentation abstracts: 2019 ECVS $28^{\text {th }}$ annual scientific meeting, July 2-4, 2019 - Budapest, Hungary. Vet Surg. 2019;48:631-84.

6. Al Naem M, Litzke L-F, Failing K, Burk J, Röcken M. Hoof kinetic patterns differ between sound and laminitic horses. Equine Vet J. 2020.https://doi. org/10.1111/evj.13311.

7. Back W, Clayton HM. Equine locomotion. In: Back W, Pille F, editors. Chapter 8, The role of the hoof and shoeing. 2nd ed. New York: Elsevier; 2013. p. 157.

8. Parks AH, Balch OK, Collier MA. Treatment of acute laminitis: supportive therapy. Vet Clin North Am Equine Pract. 1999;15:363-74.

9. O'Grady SE, Parks A. Farriery options for acute and chronic laminitis. AAEP Proc. 2008:54:355-63.

10. Clayton HM. Comparison of the stride of trotting horses trimmed with a normal and a broken-back hoof axis. Proc Ann Conv Am Assoc Equine Pract. 1998;33:289-98.

11. Schleining JA, McClure SR, Derrick TR, Wang C. Effects of industrial polystyrene foam insulation pads on the center of pressure and load distribution in the forefeet of clinically normal horses. Am J Vet Res. 2011;72: 628-33.

12. O'Grady SE. Farriery for chronic laminitis. Vet Clin North Am Equine Pract. 2010;26:407-23.

13. Hüppler M, Hagen J, Häfner FS, Geiger SM, Mäder D. Examination of the pressure force distribution affecting the hoof and its influenceability by different ground properties. Pferdeheilkunde. 2015;31:426-34.

14. Klunder P. Physical effect of heel elevation on the hoof of the horse (Physikalische Auswirkung der Trachtenhochstellung am Huf des Pferdes). Germany: Dissertation, Free University of Berlin; 2000.

15. Eliashar E, McGuigan MP, Wilson AM. Relationship of foot conformation and force applied to the navicular bone of sound horses at the trot. Equine Vet J. 2004;36:431-5.

16. Hansen N, Buchner F, Haller J, Windischbauer G. Evaluation using hoof wall strain gauge of a therapeutic shoe and a hoof cast with a heel wedge as potential supportive therapy for horses with laminitis. J Vet Surg. 2005;34: 630-6.

17. Hagen J, Hüppler M, Häfner F, Geiger S, Mäder D, Häfer FS. Modifying the height of horseshoes: effects of wedge shoes studs, and rocker shoes on the phalangeal alignment, pressure distribution, and hoof-ground contact during motion. J Equine Vet Sci. 2017;53:8-18.

18. Bellenzani MCR, Greve JMD, Pereira CAM. In vitro assessment of the equine hoof wall strains in flat weight bearing and after heel elevation. J Equine Vet Sci. 2007:27:475-80.

19. Van Eps AW, Pollitt CC. Equine laminitis: Cryotherapy reduces the severity of the acute lesion. Equine Vet J. 2004:36:255-60.

20. Van Eps AW. Therapeutic hypothermia (cryotherapy) to prevent and treat acute laminitis. Vet Clin North Am Equine Pract. 2010;26:125-33.

21. Van Eps AW, Orsini JA. A comparison of seven methods for continuous therapeutic cooling of the equine digit. Equine Vet J. 2016:48:120-4.

22. Scherlock C, Parks A. Radiographic and radiological assessment of laminitis. Equine Vet Educ. 2013;25:524-35.

23. Obel N. Studies on the histopathology of acute laminitis. Uppsala: Almquisst \& Wiksells; 1948

\section{Publisher's Note}

Springer Nature remains neutral with regard to jurisdictional claims in published maps and institutional affiliations. 